\title{
Structural Characterization of Novel Cerium Phosphate Glass Ionomer Cements (GICs) Doped with GaCl (Phthalocyanine)
}

\author{
Gomaa El-Damrawi1 ${ }^{1}$ Amal Behairy², Amr M. Abdelghany3 \\ ${ }^{1}$ Glass Research Group, Physics Department, Faculty of Science, Mansoura University, Mansoura, Egypt \\ ${ }^{2}$ The High Institute of Engineering and Technology, New Damietta, Egypt \\ ${ }^{3}$ Spectroscopy Department, Physics Division, National Research Center, Giza, Egypt \\ Email: gomaaeldamrawi@gmail.com
}

How to cite this paper: El-Damrawi, G. Behairy, A. and Abdelghany, A.M. (2018) Structural Characterization of Novel Cerium Phosphate Glass Ionomer Cements (GICs) Doped with $\mathrm{GaCl}$ (Phthalocyanine). New Journal of Glass and Ceramics, $\mathbf{8}$, 23-38.

https://doi.org/10.4236/njgc.2018.82003

Received: May 18, 2018

Accepted: June 19, 2018

Published: June 22, 2018

Copyright $(9) 2018$ by authors and Scientific Research Publishing Inc. This work is licensed under the Creative Commons Attribution International License (CC BY 4.0).

http://creativecommons.org/licenses/by/4.0/

\begin{abstract}
Cerium Pyrophosphate glass is prepared and investigated by different structural techniques. Resin modified glass ionomer cements (RGICs) of pyro cerium phosphate $\left(40 \mathrm{CeO}_{2}-60 \mathrm{P}_{2} \mathrm{O}_{s}\right)$ composition doped with different concentrations from $\mathrm{GaCl}$ Phthalocyanine $\left(\mathrm{C}_{32} \mathrm{H}_{16} \mathrm{ClGaN}_{8}\right)$ have been also prepared and studied for the first time. Different techniques have been applied to shed light on the structural changes induced upon addition of GaCl-Phthalocyanine. The corresponding changes in material structure are widely approved by results of ${ }^{31} \mathrm{P}$ magic angle spinning nuclear magnetic resonance (MAS-NMR), $\mathrm{X}$-Ray diffraction and FTIR spectroscopy. The network structure of both base glass and GIC free from $\mathrm{C}_{32} \mathrm{H}_{16} \mathrm{ClGaN}_{8}$ is confirmed to be amorphous. Doping even with little concentration from $\mathrm{GaCl}$-Phthalocyanine leads to changing the network structure from amorphous to a highly crystalline one. Formulation of $\mathrm{GaCl}$-Phthalocyanine with water soluble acid leads to monocrystalline structure due to monoclinic lattice structure of Phthalocyanine. Carbonated hydroxyl cerium and gallium phosphate structural phases are evidenced to be formed upon GaCl-Phthalocyanine addition. Presence of such bioactive phases can support that the prepared GICs of considerable $\mathrm{C}_{32} \mathrm{H}_{16} \mathrm{ClGaN}_{8}$ concentration (1 and $1.5 \mathrm{~mol} \%$ ) can be applied as biocompatible materials used in biodental applications. The morphologies of some selected samples were characterized by SEM. The micrographs have revealed that formulating of cerium phosphate powder of the amorphous glass with polymeric acid successfully led to the formation of $\mathrm{CePO}_{4}-\mathrm{H}_{2} \mathrm{O}$ nanofibrous bundles. But formulation with GIC containing GaCl-Phthalocyanine can simply form co-aligned and elongated nanofibers $(15-40 \mathrm{~nm}$ thick and up to ca. $1.2 \mathrm{~m}$ long). The formed nanofibers are mainly consisted of hydrated and
\end{abstract}


carbonated $\mathrm{CePO}_{4}$ and $\mathrm{GaPO}_{4}$ nanocrystals. The hardness of the cemented material increases with increasing $\mathrm{GaCl}-\mathrm{Phthalocyanine} \mathrm{concentrations.}$

\section{Keywords}

Glass Ceramics-GIC-Crtstalline Structure, Spectroscopy

\section{Introduction}

There is an increasing interest in metal phosphates composites due to their relevance in biology and materials science [1] [2]. It is known that addition of modifier oxide to $\mathrm{P}_{2} \mathrm{O}_{5}$ leads to disruption of P-O-P bridges [3] [4]. At first, $\mathrm{PO}_{4}$ branching units in $\mathrm{Q}^{3}$ configuration $(\mathrm{Q}$ is phosphors cation, $\mathrm{n}$ is the number of bridging bonds) can form metaphosphate composition. The latter species are transformed to two-connected middle units of $\mathrm{Q}^{2}$ configuration which represent pyrophosphate composition. In the end, isolated $\mathrm{PO}_{4}$ units $\left(\mathrm{Q}^{1}\right.$ and $\mathrm{Q}^{0}$ orthophosphate) are occurred at extremely high concentration from modifier oxide (>50 mol\%). At metaphosphate composition, i.e. in glasses of less than $30 \mathrm{~mol} \%$ modifier oxide and more than 70 mole $\% \mathrm{P}_{2} \mathrm{O}_{5}$, chain and/or ring structures of $\mathrm{PO}_{4}$ middle groups are formed. With further modifier addition, the chains become shorter and at the pyrophosphate composition, i.e. in glasses of $40 \mathrm{~mole} \%$ modifier, the $\mathrm{PO}_{4}$ dimers (molecular complex consisting of two identical molecules linked together) are the dominate species. The corresponding changes are widely presented by results of ${ }^{31} \mathrm{P}$ magic angle spinning nuclear magnetic resonance (MAS NMR) and vibrational spectroscopy. Many of such results are reviewed in references [3] [4].

When the powder of the oxide glass is formulated with some types of weak polymeric acids, the well-formed material is called glass ionomer cement. Expression of a glass-ionomer cement (GIC) is devoted only to a material which involves a proper acid-base reaction as a part of its setting process [5] [6]. The acid is a water-soluble polymer and the base is a special powder of specific type of glass or glass ceramic of basic character. $\mathrm{P}_{2} \mathrm{O}_{5}$ based glass systems are the most recommended type because its basic reaction is higher than that of silicate and borate glasses. Therefore, the origin of glass ionomer cements should be based on reaction between acid and the powder of phosphate glass.

Most of simple and conversional GICs were brittle materials. Therefore several trials have been devoted to enhance the physical properties by the addition of some types of supported materials such as $\mathrm{TiO}_{2}-\mathrm{Cr}_{2} \mathrm{O}_{3}-\mathrm{Al}_{2} \mathrm{O}_{3}, \mathrm{Ag}_{2} \mathrm{O}, \mathrm{ZrO}, \mathrm{SrO}$, $\mathrm{CrF}_{2}$ [3] [7] [8] [9]. In addition, they play the role of compatibility enhancement of the material to be most proper in the field of bio-applications [10] [11]. The additive materials can also stimulate the nucleation and crystallization processes of hydroxyphosphate phases which are the essential mineral phase of bone and teeth. Some specific types of materials can be added as dopant to play an effec- 
tive role in improving the physical properties and widening the range of applications [3] [4].

GICs are considered the most appropriate materials in the field of bio-dental applications [4] [5] [6] [7] [8]. Several types of (MGICs) are applied as alternatives for both amalgam and resin composites which possess several shortcomings such as: 1) Resin composite lacks the characteristic of good adhesion to the bone of tooth; 2) It undergoes polymerization shrinkage which leads to crack propagation on setting; 3) Amalgam is corrosive material and its vapor is toxic. From these reasons, (GICs) were considered to possess several advantages that resins and dental amalgam do not make.

Several types of GICs modified by specific types of supporting materials have been previously studied [3] [4] [5] [6]. But modification of GIC with GaCl-Phthalocyanine species $\left(\mathrm{C}_{32} \mathrm{H}_{16} \mathrm{ClGaN}_{8}\right)$ as an organic agent for nucleation, antimicrobial and crystallztion processes has not yet reported. Therefore this study is aimed to determine (for the first trial) the structure role of the dopant $\mathrm{C}_{32} \mathrm{H}_{16} \mathrm{ClGaN}_{8}$ molecules in the modified pyro cerium phosphate based GIC.

\section{Experimental}

\subsection{Material Preparation}

Binary Cerium phosphate glass with composition $40 \mathrm{CeO}_{2} \cdot 60 \mathrm{P}_{2} \mathrm{O}_{5}$ has been synthesized using analytical grade chemicals using ordinary melt quenching technique. Calculated batches of the starting raw materials were mixed including the appropriate amounts of $\mathrm{CeO}_{2}$ and $\mathrm{NH}_{4} \mathrm{H}_{2} \mathrm{PO}_{4}$ as a source of $\mathrm{P}_{2} \mathrm{O}_{5}$. The mixture was heated in a porcelain crucible at $300^{\circ} \mathrm{C}$ for $30 \mathrm{~min}$. in order to evaporate ammonia, water, and nitrogen. Then, the product was melted between 1100 to $1350^{\circ} \mathrm{C}$ for an hour. To assure the homogeneity, the previous oxides were added to the melt in the crucibles in small parts and the melts were stirred before each addition. After refining, the melts were quenched on a stainless steel plate. The obtained glasses were homogenous, transparent and there was no sign of devitrification. Because of the phosphate glasses have higher tendency to absorb moisture, the glass samples were sealed with silica gel pellets in sacks of plastic and kept in desiccators until required. GICs were prepared by formulating the glass powder with a polymeric acid of type (Ketac Molar Easymix, Germany). They are mixed und swirled until a homogenous past is obtained.

\subsection{Measurements}

Infrared absorption spectra of the glasses were recorded in the range of $400 \mathrm{~cm}^{-1}$ to $4000 \mathrm{~cm}^{-1}$ at ambient temperature by a spectrophotometer type (Mattson 5000 FTIR spectrometer). The measurements were carried out on powdered glass samples which is mixed with $\mathrm{KBr}(1 \mathrm{wt} \%)$. The measurement process occurred immediately after the mixture compression with a load of 5 tons $/ \mathrm{cm}^{2}$.The distribution of $\mathrm{Q}^{\mathrm{n}}$ of phosphate units can be obtained from ${ }^{31} \mathrm{P}$ NMR spectra of 
some selected samples. The measurements were analyzed using a high resolution solid state MAS NMR type (JEOL RESONANCE GSX-500 spectrometer). The obtained spectra were recorded at high external magnetic field $(11.747 \mathrm{~T})$, at frequency of $160.47 \mathrm{MHz}$ and spinning rate of $17 \mathrm{KHz}$. X-ray diffraction pattern was obtained by using X-ray diffractometer type (Philips PW 1729) with a compact analyzer system 1840 and 8203A/02 chart recorder. Surface modification and microstructure of glass samples were examined using a Scanning Electron Microscope (SEM) equipped with EDX unit. Operated and accelerating voltage of $25 \mathrm{KV}$, with a magnification up $400,000 \mathrm{X}$ and resolution for W. $(3.5 \mathrm{~nm})$ is the feature of the used SEM. The technique of gold plated samples has been applied. The average grain size of the various specimens was $60 \mu \mathrm{m}$.

\section{Results and Discussion}

Very low levels of $\mathrm{GaCl}$-Phthalocyanine (0 - $1.5 \mathrm{~mol} \%)$ within the glass ionomer cement of the cerium phosphate glass can drastically influence its propensity to crystallize as well as change structure and morphology of the final formed phases. Figure 1 reflects the effect of a small addition of the dopant material on the visual or appearance properties. Change the color from transparent yellow to green to dark blue may lead to precipitation of some crystalline phases containing gallium cations.

\subsection{XRD Analysis}

To understand how these small compositional changes affect the material structure via the doping process, different techniques and spectroscopic tools have been applied. Correlation between data obtained from these techniques can provide a unique insight into the structure of these GICs and how they change during phase separation and crystallization processes. Because of the large differences in molecular weight between the glass constituents, and particularly the significant effects of $\mathrm{C}_{32} \mathrm{H}_{16} \mathrm{ClGaN}_{8}$, X-Ray diffraction is a highly informative technique for this type of research. In addition, local structural information on the main glass-forming elements of phosphate nuclei was obtained from solid-state NMR spectroscopy.

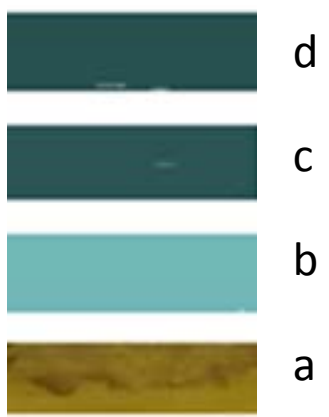

Figure 1. (a) Poured cerium phosphate glass and (b) glass ionomer cement with the addition of 0.5 to $1.5 \mathrm{~mol}_{32} \mathrm{C}_{32} \mathrm{H}_{16} \mathrm{ClGaN}_{8}$; (b)-(d)showing the effect on the appearance of the studied materials. 
The addition of GaCl-Phthalocyanine has been shown to be very effective in enhancing the crystallization of GICs, as is shown in Figure 2. This is of particular interest as it enables control over the crystallization behavior of the studied GICs. Then very low levels of $\mathrm{GaCl}$-Phthalocyanine have been shown to change the structure of the present investigated GIC systems and therefore this is also of interest. Mixing effect of $\mathrm{CeO}_{2}$ and chlorogallium species in the matrix of GIC should play a good role in improvement of structure and properties of the material network and consequently induces high resistance to corrosion processes through formation of some types of fined grained crystals in the main matrix. In such situation, fine grained chloro-gallium phosphate crystals and/or hydroxyl cerium phosphate, gallium cerium chlorophosphate, and phthalocyanine dimmers are the most suggested formed phases. To confirm this aspect, changes of the $\mathrm{PO}_{4}$ units in the corresponding glasses were also analyzed by XRD and FTIR spectroscopy.

Comparisons between XRD patterns of the studied materials with the $\mathrm{Ga}\left(\mathrm{PO}_{3}\right)^{3}$ crystal [12] [13] were made. It was noteworthy realized that both XRD and FTIR spectra of GIC containing $\left(\mathrm{C}_{32} \mathrm{H}_{16} \mathrm{ClGaN}_{8}\right)$ involve very intensive sharp peaks even at a little addition of the dopant. This means that gallium chloride molecules are considered as good scatters for X-rays. This may because Ga-O bonds are longer than both P-O and Ce-O bonds. Thus FTIR and XRD spectra are well resolved. So X-ray diffraction experiments are excellent in a search for changes in $\mathrm{Ga}-\mathrm{O}$ environments even if small concentration from the dopant material is added. Therefore, cerium phosphate based GIC were prepared only in a small range with molar fractions of $\mathrm{C}_{32} \mathrm{H}_{16} \mathrm{ClGaN}_{8}$ (0 to 1.5 mol\%).

The XRD patterns of investigated samples are shown in Figure 2. It illustrates the marked difference in structural changes between the reference glass sample

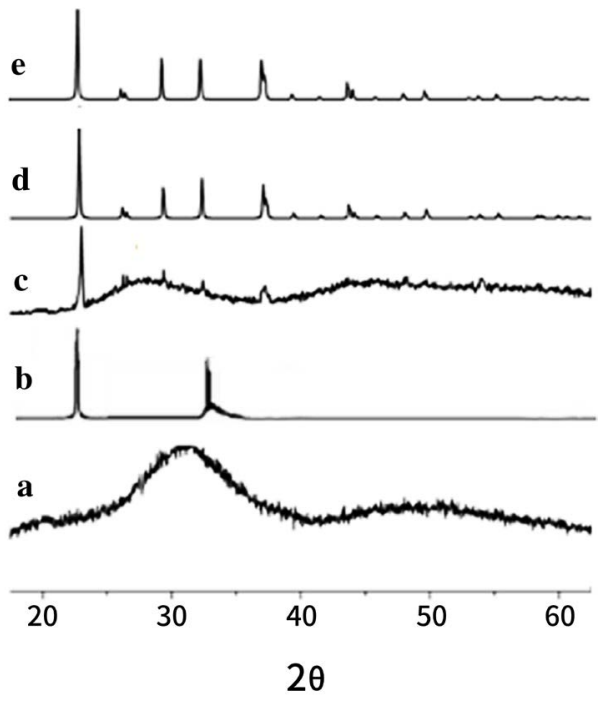

Figure 2. XRD patterns of (a) base glass, (b) base Gallium choloride and (c), (d) and (e) for GICs containing 0.5, 1 and $1.5 \mathrm{~mol} \% \mathrm{C}_{32} \mathrm{H}_{16} \mathrm{ClGaN}_{8}$. 
(cerium phosphate glass, spectra a), the reference $\mathrm{C}_{32} \mathrm{H}_{16} \mathrm{ClGaN}_{8}$ ) GIC (spectra, b) and compares the percentage of the dopant in GICs systems (c, d and e). The spectra of the base glass of composition $40 \mathrm{CeO}_{2}-60 \mathrm{P}_{2} \mathrm{O}_{5}$ are presented by Figure 2(a). The corresponding spectrum exhibits a broad spectral band at low diffraction angles $\left(25^{\circ}-40^{\circ}\right)$ confirming a structural disorder characteristic of amorphous network of the base glassy material. On the other hand, spectra (b) represent XRD patterns of the formulated $\mathrm{C}_{32} \mathrm{H}_{16} \mathrm{ClGaN}_{8}$ with polymeric acid. It can observe that there are two characteristic sharp diffraction peaks (at about $23^{\circ}$ and $34^{\circ}$ ) representing the carboxyle groups balanced by gallium cations (COO)Ga. Crystal structure analysis of the two line spectra confirm the presence of hydroxyl gallium phthalocyanine type and chloro gallium phthalocyanine crystalline type of monoclinic structure [13] [14] [15]. The spectra (c), (d) and (e) represent XRD spectra of cerium phosphate based GIC containing different $\mathrm{C}_{32} \mathrm{H}_{16} \mathrm{ClGaN}_{8}$ concentrations ( 0.5 and from 1 and $1.5 \mathrm{~mol} \%$ ) respectively. It can be shown that some sharp diffraction peaks are superimposed on the broad diffraction patterns (b) in GIC of $0.5 \mathrm{~mol} \% \mathrm{C}_{32} \mathrm{H}_{16} \mathrm{ClGaN}_{8}$. These spectra may be considered to be formed from two components. One is due to the amorphous matrix of the glass (of spectra a) and the crystalline matrix of the resined $\mathrm{C}_{32} \mathrm{H}_{16} \mathrm{ClGaN}_{8}$ (of spectra b). Therefore the obtain spectra of glass of $0.5 \mathrm{~mol} \%$ $\mathrm{GaCl}$ is built from a broad hump with some sharp diffraction lines. More sharper diffraction peaks are appeared with increasing gallium chloride to reach 1.5 mol\%. In such a case the broad diffraction hump is totally disappeared, (spectra $\mathrm{d}$ and e) which confirms the presence of the highest crystalline structure at these compositions. These changes are summarized in Figure 3, which represents change of crystallinity with glass composition. It can be shown from this figure that the crystallinty increases with increasing $\mathrm{C}_{32} \mathrm{H}_{16} \mathrm{ClGaN}_{8}$ concentration to reach its saturated values at about $1 \mathrm{~mol} \%$.

Then from Figure 2 and Figure 3, one may expect that the crystallization

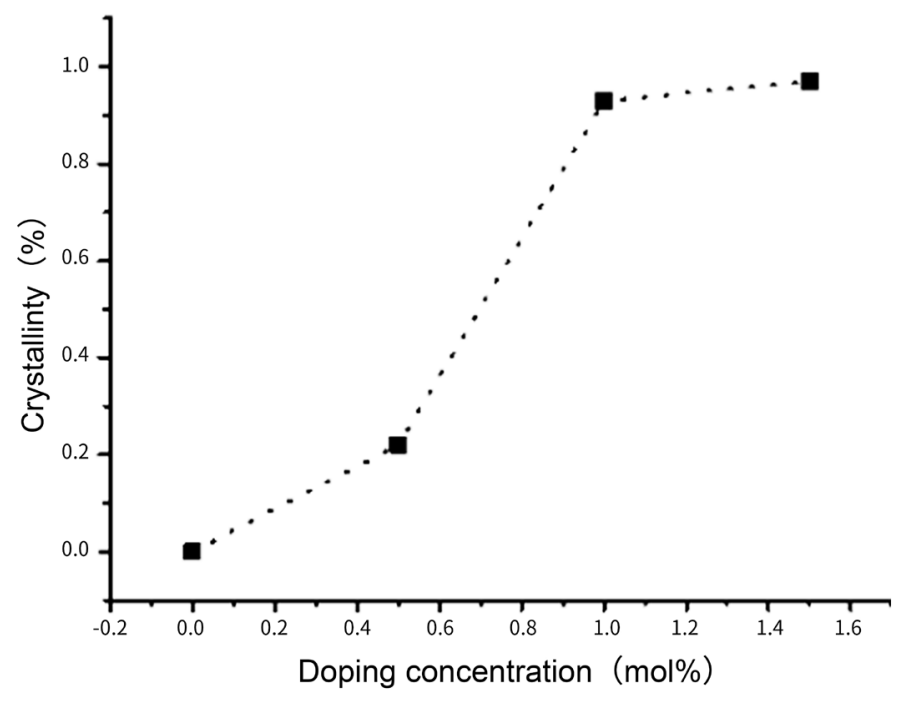

Figure 3. Dependence of crystallinity on $\mathrm{C}_{32} \mathrm{H}_{16} \mathrm{ClGaN}_{8}$ concentration. 
process is offered mainly by effect of galliumcholoride since the material containing even limited doping level $(0.5 \mathrm{~mol} \%)$ is crystallized prior to undergoing the second step of crystallization (at 1 and $1.5 \mathrm{~mol} \%$ ). The number of diffraction lines in all doped GIC is the same but change in intensities is the most observed changeable parameter. This means that the type of the formed crystalline phases is similar but the content of the separated phases increases with increasing $\mathrm{C}_{32} \mathrm{H}_{16} \mathrm{ClGaN}_{8}$ concentrations. There are additional phases are formed by comparing spectra a and $\mathrm{b}$. Besides the hydroxyl-gallium phthalocyanine and chloro-gallium phthalocyanine crystalline phases, $\mathrm{GaPO}_{4}$ or $\mathrm{GaCePO}_{4}$ hydrated and carbonated species are also formed in GICs matrix [15] [16] [17] [18] [19]. This interpretation may account on the presence of several diffraction lines in spectra of cerium phosphate based GIC modified by $\mathrm{C}_{32} \mathrm{H}_{16} \mathrm{ClGaN}_{8}$ (spectra $c, d, e$ ). Presence of such crystalline hydroxyapatite phases are considered to be useful for the material to be used in the field of bio dental and bioactive application.

On mixing powder of binary $\mathrm{CeO}_{2}-\mathrm{P}_{2} \mathrm{O}_{5}$ glass with acid (water-soluble polymer), the acid attacks the matrix of glass and $\mathrm{C}_{32} \mathrm{H}_{16} \mathrm{ClGaN}_{8}$ resulting in surface degradation. As a result of degradation, release of metal ions such as cerium and gallium cations should occur. The released ions can react with the hydrated or the carbonated phosphate units and the carbonated hydroxyapaptite phases are constructed [10] [11]. Presence of different line spectra leads to formation of different phosphate groups containing cerium or gallium or both cations. Increasing of $\mathrm{C}_{32} \mathrm{H}_{16} \mathrm{ClGaN}_{8}$ as a dopant material was found to enhance the cement structure via forming $\mathrm{GaPO}_{4}$ crystalline species. The crystal structure of $\mathrm{Ce}_{2} \mathrm{Ga}\left(\mathrm{HPO}_{3}\right)_{3}\left(\mathrm{PO}_{3}\right)$ exhibits a complicated 3D framework based on $\mathrm{CeO}_{6}$ and $\mathrm{GaO}_{6}$ octahedral connected by $\mathrm{HPO}_{3}$ and $\mathrm{H}_{2} \mathrm{PO}_{3}$ anions via corner- or edge-sharing [10] [11]. Finally interactions between (COO)Ce and $\mathrm{GaPO}_{4}$ species leads to formation of more crystallized phosphate phases containing $\mathrm{Ga}$ and Ce cations. These crystallite phases are relevant to support the fabrication of bone tissue engineering scaffolds from cerium phosphate bioglass which should exhibit tailored porosity, controlled crystallinity and enhanced bioactivity [14] [15] [16].

\subsection{FTIR and NMR Spectroscopy}

Formation of the above mentioned crystalline phases is highly evidenced also from FTIR spectra of GIC containing different concentrations from GaCl-Phthalocyanine. The appearance of new sharp FTIR absorbance peaks (Figure 4) are assigned to Ga or Ce vibration in the crystalline carbonated cerium phosphate phase (poly acid salt). Figure 4 presents FTIR spectra of both glasses after and before the reaction with organic polymeric acid. The cement phase is only present in glass after the reaction process. The cement species are presented by presence of new splitting absorbance peaks around $1950 \mathrm{~cm}^{-1}$ (Figure 4, curve b) which are totally absent in the glass before the reaction process (curve a). Due to the acid-base reaction, the surface of the glass becomes 


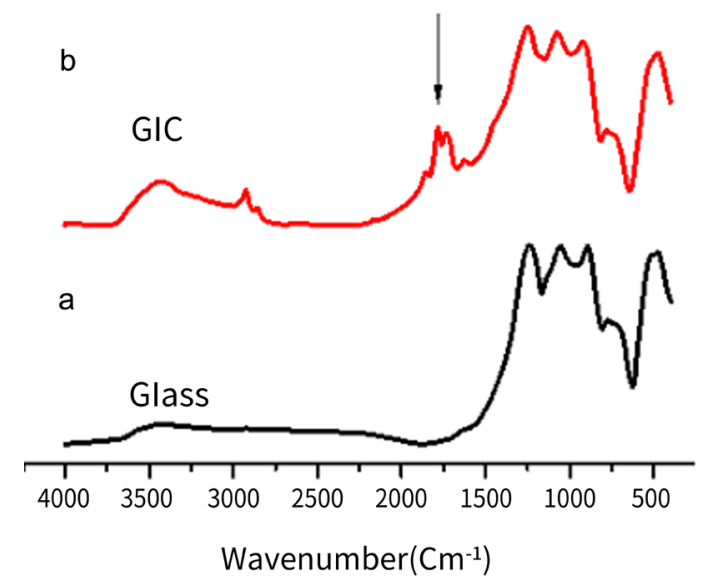

Figure 4. FTIR absorbance spectra of (a) base glass and (b) for GIC.

a phousphours hydrogel (P-OH) which forces both gallium and cerium cations to link with hydrated phouphor units. Then on mixing powder of glass and liquid, the self cure polymerization reaction begin and setting can be occurred [6] [8].

More evidences for acid-base reaction can be considered from NMR result of phosphors nuclei. It can be shown from Figures 5 (a)-(b) that the intensity and the fullwidth at half maximum (FWHM) of the NMR resonance peak are highly affected by the acid-base reaction. The intensity of the resonance NMR peak is decreased and FWHM is increased. These changes are considered as good evidences for the degradations processes which are simply produced due to the reaction between the glass and the acid [20].

By considering FTIR absorbance spectra of doped samples (Figure 6), they exhibited many absorption bands at 3500, 3000, 1910, 1000, 1465, 1151 and 750 $\mathrm{cm}^{-1}$. The presence of a large band at $3500 \mathrm{~cm}^{-1}$ is corresponding to the $\mathrm{O}-\mathrm{H}$ stretching frequency [6] [7] [8]. The peak at $1151 \mathrm{~cm}^{-1}$ is assigned to the stretching vibration of the $\mathrm{C}-\mathrm{N}$ bond of gallium phosohate structural units [6] [7] [8], while the peak at $1465 \mathrm{~cm}^{-1}$ is due to the deformation mode of phosphate species. The intensity of the peaks at $740 \mathrm{~cm}^{-1}$ is decreased while peak at 1900 is increased with increasing $\mathrm{GaCl}$ Phthalocyanine concentrations. This behavior may lead to suggest that NBO component was frequently removed by effect of increasing dopant concentration. This may mean that the degradation induced by acid-base reaction could be amended by the dopant cations. This result is further supported, since presence of Ce-O-C or $\mathrm{Ga}-\mathrm{O}-\mathrm{PO}_{4}$ bond formed by the interaction between cerium oxide and the carboxylate group of GIC or Ga are evidenced to be present $\left(1680 \mathrm{~cm}^{-1}\right)$. The intensity of band at 1680 is grown and became resolved (Figures 6(b)-(d)). However, spectra shows the presence of a band at $3430 \mathrm{~cm}^{-1}$ corresponding to the $\mathrm{O}-\mathrm{H}$ stretching frequency and a band at $1676 \mathrm{~cm}^{-1}$ to the bending vibration of associated water. The formation of Ce-O-C bond indicates that there is a degree of interaction between the organic and inorganic components via condensation reaction in the initial GIC precursor, 


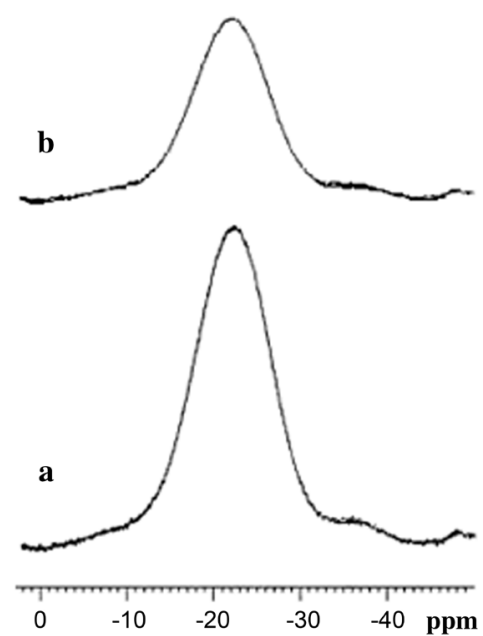

Chemical Shift ( ppm)

Figure 5. NMR spectra of (a) base glass and (b) for GIC.

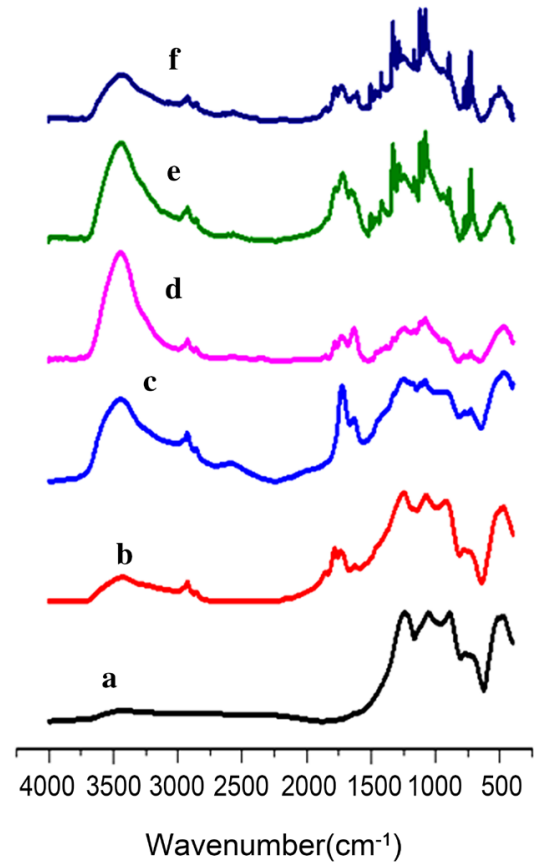

Figure 6. FTIR absorbance spectra of (a) base glass and (b) for GIc containing gallium clorid, (c, d, e, e, f) GIC of cerium phosphate containing 0, 5, 0, 8, 1 and $1.5 \mathrm{~mol} \%$ $\mathrm{C}_{32} \mathrm{H}_{16} \mathrm{ClGaN}_{8}$.

while this type of GIC strengthening can assist the formation of mesopores. The most to be noticed from Figure 6 that the absorbance peaks represented carboxyle groups $\left(1680 \mathrm{~cm}^{-1}\right)$ is splited into differed components suggesting that the interaction is carried out due to $\mathrm{GaCl}$ Phthalocyanine modifications. In addition, in doped GIC, all FTIR spectra (Figure 6) clearly show sharpening of the peaks in the spectral region $600-1900 \mathrm{~cm}^{-1}$ which is associated with crystalline phosphate units containing $\mathrm{Ga}\left(\mathrm{PO}_{4}\right)$ or $\mathrm{CePO}_{4}$ or both. Formation of such phases additionally accounts for the sharpening of the shoulder at about $600 \mathrm{~cm}^{-1}$ with in- 
creasing $\mathrm{C}_{32} \mathrm{H}_{16} \mathrm{ClGaN}_{8}$ concentration. However, it is seen that the sharpening occurs more rapidly from the first $\mathrm{C}_{32} \mathrm{H}_{16} \mathrm{ClGaN}_{8}$ addition. In comparison with $\mathrm{C}_{32} \mathrm{H}_{16} \mathrm{ClGaN}_{8}$ free glass, very clear changes can be seen in the region 500 - 1900 $\mathrm{cm}^{-1}$. The peak developed at 590 may be explained by the presence of metallic ions such as Ga or Ce [13] [14] [15]. The typical crystalline phosphate or apatite split bands at $560 \mathrm{~cm}^{-1}$ and $613 \mathrm{~cm}^{-1}$ are clearly present for all Ga containing glasses. The spectra indicating the presence of crystalline phases which have another band at about $960 \mathrm{~cm}^{-1}$ corresponding to the P-O stretch in the phosphate tetrahedron. As is clear from Figure 5, it can be observed that strong changes can be seen in the spectra with increasing $\mathrm{C}_{32} \mathrm{H}_{16} \mathrm{ClGaN}_{8}$ concentrations.

Results based on both FTIR and XRD spectra have shown sharp peaks in glasses containing $\mathrm{GaCl}$ Phthalocyanine. The added agents should act as both stimulator for nucleation and crystallization of cerium phosphate phases which are the essential mineral phase of bone and teeth. Mixing effect of $\mathrm{CeO}_{2}$ and $\mathrm{GaCl}$ plays a good role in improvement of hardness and compactness of the material network and consequently high corrosion resistance. Figure 7 represents changes of the hardness number with concentration. $\mathrm{H}_{\mathrm{v}}$ increases frequenty with GaCl Phthalocyanine addition.

The fast increase of $\mathrm{Hv}$ (Figure 8) is considered as an additional evidence for acid-base reaction together with increasing doping concentration which was documented from both XRD and FTIR data. It can be shown from Figure 2 and Figure 6 that the intensity of XRD diffraction and FTIR absorbance peaks of GIC are highly affected by the doping concentration. The intensity of XRD, FTIR peak and the hardness number increase with increasing $\mathrm{GaCl}-\mathrm{Ph}$ thalocyanine concentrations. These changes give additional confirmation that $\mathrm{C}_{32} \mathrm{H}_{16} \mathrm{ClGaN}_{8}$ can

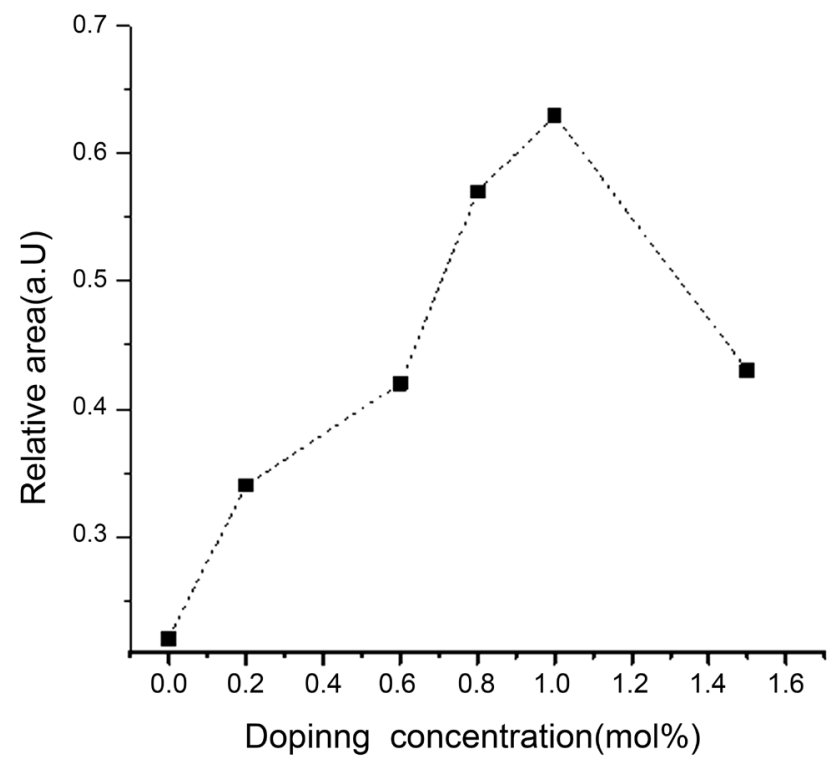

Figure 7. Change of relative area of FTIR spectral band $\left(1960 \mathrm{~cm}^{-1}\right)$ of GIC of cerium phosphate with doping concentration. 


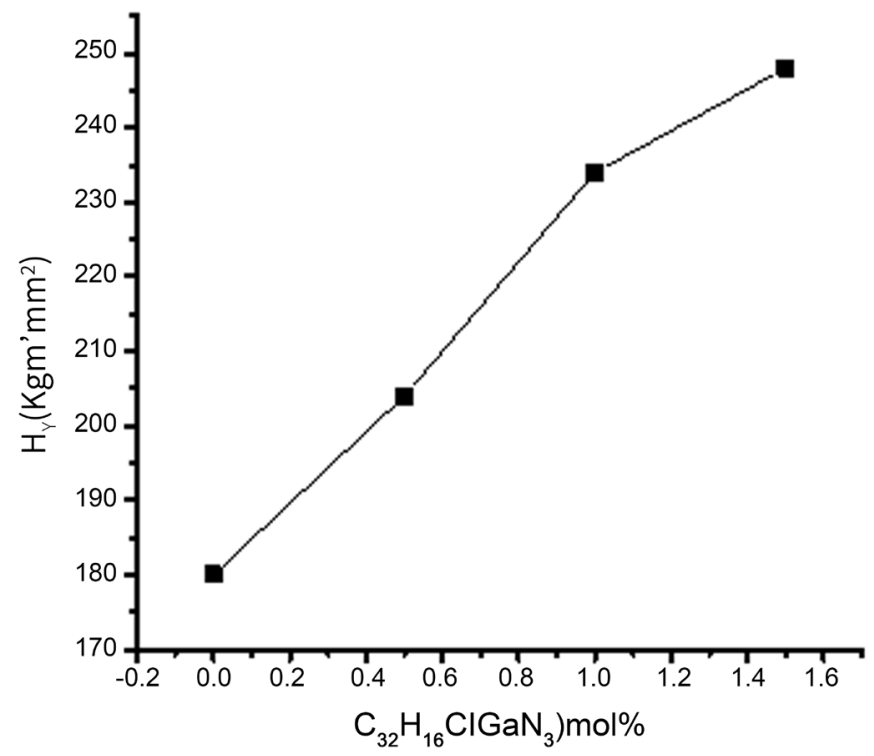

Figure 8. Relation between hardness nimber (Hv) and doping concentration.

simply activate the interaction of organic and the inorganic species which results in decreasing degradations processes that takes place by attacking the acid to the surface of the glass. As a consequence the hardness of the glass shows an effective increasing trend.

\subsection{Morphological Studies (SEM)}

Recent investigations have evidenced that the properties of $\mathrm{CePO}_{4}$ nano species depend strongly on, morphology and crystallinity relationships [18]-[23]. The controlled synthesis of these nanomaterials often requires the employment of sensitive and specific technique. The applied method of acid-base reaction is considered between the most suitable routes. The addition of chelating or complexing additives such as $\mathrm{GaCl}$-Phthalocyanine applied as surfactants is often necessary to control the synthesis conditions. The latter may be generally needed to obtain the desired morphology, including preparation variables such as the chosen $\mathrm{Ce}$ and phosphate the $\mathrm{P} / \mathrm{Ce}$ ratio which is 1.5 in the present study. This higher ratio (than 1:1) is enough to obtain more uniform and highly-elongated (high aspect ratio) morphologies with a better crystallinity as is evidenced from Figure 2(d) and Figure 2(e). These characteristics become essential to improve the biomedical application of the used materials.

The morphology and amorphous structure of $\mathrm{CePO}_{4}$ glass were characterized by Scanning Electron Microscopy. The micrograph of base glass is presented by Figure 9 which shows homogenous glass network. Noteworthy, formulating of cerium phosphate power of the amorphous glass with polymeric acid successfully led to the formation of $\mathrm{CePO}_{4}-\mathrm{H}_{2} \mathrm{O}$ nanofibrous bundles (Figure 10). But for mutation with GIC containing GaCl-Phthalocyanine can simply form co-aligned and elongated nanodifused species (Figure 11) which is transformed to more aligned thinner elongated nanofibers at (Figure 12). The well formed 


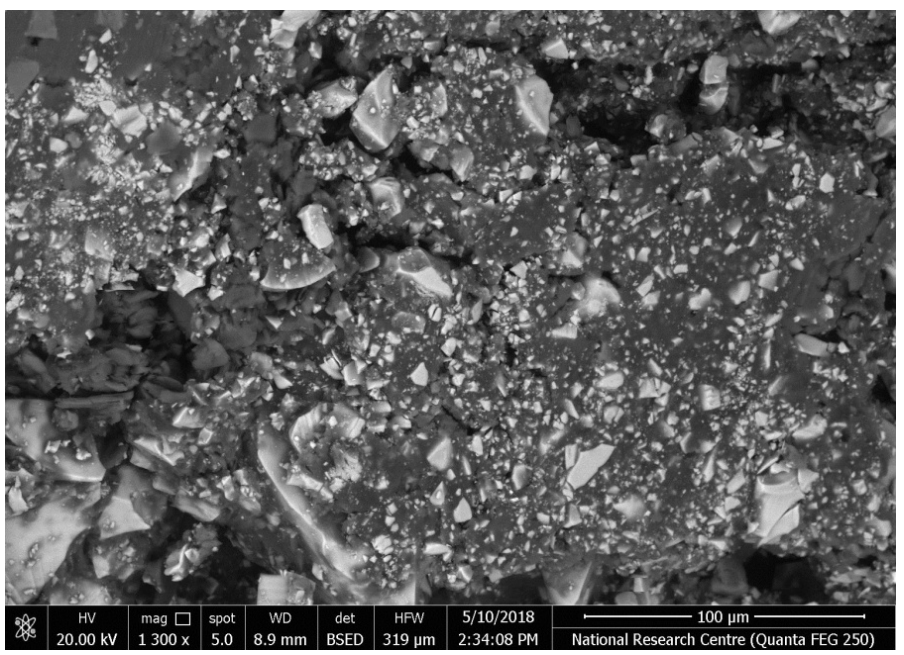

Figure 9. SEM of base cerium phosphate glass.

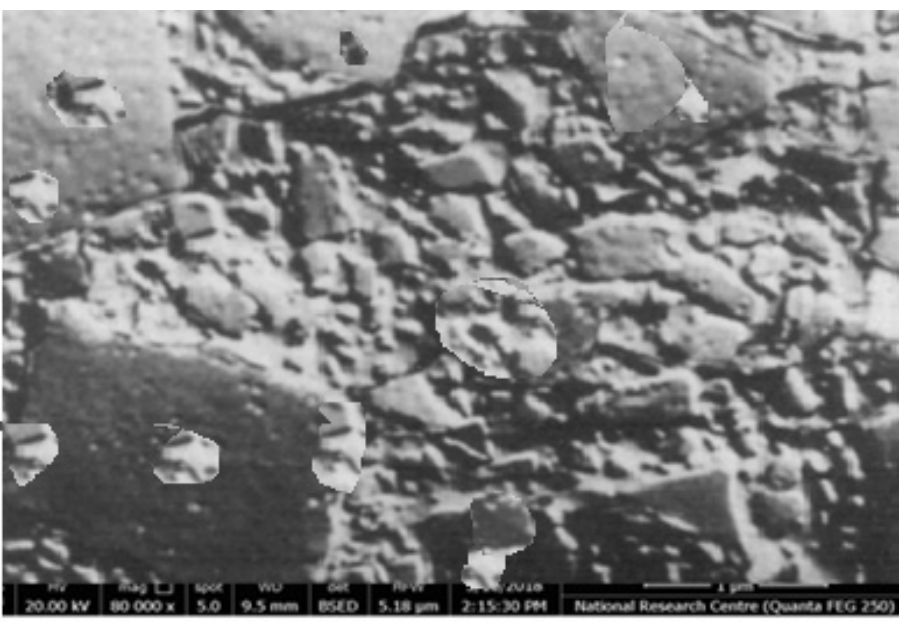

Figure 10. GIC (powder of cerium phosphate glass formulated with polymeric acid) showing pitted glass particles and embedded in a polysalt gel matrix.

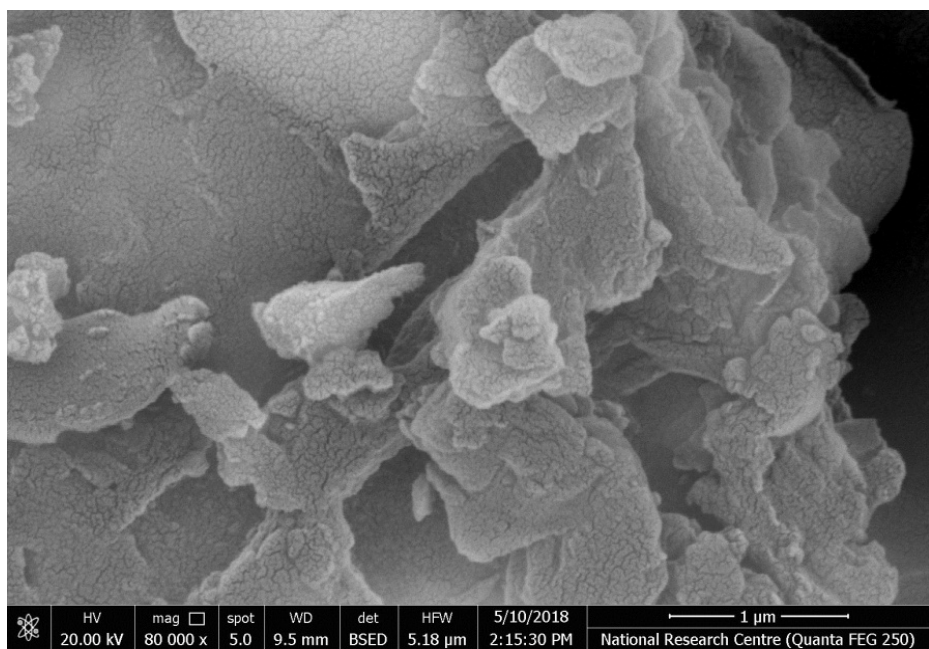

Figure 11. GIC containing $0.5 \mathrm{~mol} \% \mathrm{GaCl}$ Phthalocyanine, the morphology appears as bundles like structure. 


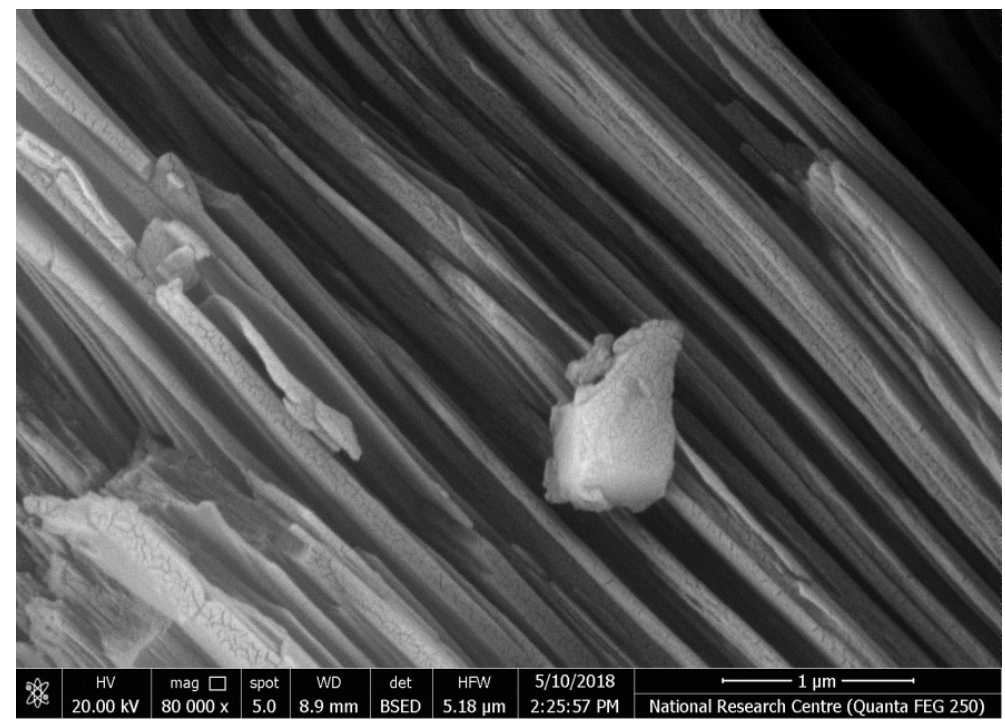

Figure 12. GIC containing $1.5 \mathrm{~mol} \% \mathrm{GaCl}$ Phthalocyanine, the morphology appears elongated fibers or wafers like structure.

fibers are characterized with $10-20 \mathrm{~nm}$ thick and up to ca. $1.2 \mathrm{~m}$ long, as shown in Figure 12. The formed nanofibers consisted of $\mathrm{CePO}_{4}$ and $\mathrm{CaPO}_{4}$ nanocrystals, with better-elongated shapes which are considered to be useful for using the materials in the field of tissue engineering or bio scaffolds applications.

Given the strong affinity of carboxylate or peptide moieties for cerium phosphate species [24] [25] [26], it makes the structure to simultaneously incorporating the precursor phosphate moieties which called (grafting) throughout the self-assembled nanofibrous network can produce scaffold matix of elongated nanofiber shape (Figure 12).

As important advantage, this acid-base reaction can be performed under relatively mild conditions ( $\mathrm{pH}$ around $4-4.5$ ) avoiding the strict requirements of using a great excess amount of phosphates of very low $\mathrm{pH}$ values $(<1.5)$. Such conditions, are often necessary to obtain high aspect ratio of elongated $\mathrm{CePO}_{4}$ nanofibers functional gels [27] [28], and they have been also successfully employed as templates in the transcription of nanofibrous inorganic materials and hybrid biomaterials [28] [29] [30].

\section{Conclusion}

$\mathrm{XRD}$ and SEM analysis provides the crystalline nature and the morphology of the metal complexes. Most of the added $\mathrm{GaCl}$ molecules exhibited realble improvement in crystallinity, morphological and structural properties. The current studies are seeking to shed light on cerium phosphate based GIC containing small additives from $\mathrm{GaCl}-\mathrm{Phthalocyanine} \mathrm{with} \mathrm{unusual} \mathrm{properties} \mathrm{and} \mathrm{different}$ potential applications. For example, GIC-based nanocomposite species, containing $\mathrm{GaCl}$ nanocrystals as functional components, were successfully prepared and cross-linked using acid-base reaction between the organic and inorganic constituents of GIC. XRD and SEM showed that cerium phosphate glass and 
glass ionomer cement retained its amorphous characteristics after and before the reaction between the glass powder and the polymeric acid, while formulating cerium phosphate powder with both polymeric acid and $\mathrm{GaCl}$-Phthalocyanine results in producing nanocrystals which retained crystalline morphology in the nanocomposites after cross-linking, processes. Some crystalline phases are formed in a bundle like shape at low $\mathrm{GaCl}$ Phthalocyanine concentration, 0.5 mol\%. The bundle morphology is transformed to Co-elongated fiber or wafers like shape at higher concentration. The morphology of crystalline elongated structure recommend the material to be used in different potential applications such as the field of tissue engineering or bio scaffolds applications.

\section{References}

[1] Walawalkar, M.G., Roesky, H.W. and Murugavel, R. (1999) Discrete Silanetriols: Building Blocks for Three-Dimensional Metallasiloxanes. Accounts of Chemical Research, 32, 117-126.

[2] Dutta, D.P. and Jain, V.K. (2000) Synthesis and Characterization of Phosphinic and Phosphate Complexes of Gallium(III) and Indium(III). Phosphorus, Sulfur, and Silicon and the Related Elements, 166, 15-26.

[3] Brow, R.K. (2000) Review: The Structure of Simple Phosphate Glasses. Journal of Non-Crystalline Solids, 263-264, 1-28. https://doi.org/10.1016/S0022-3093(99)00620-1

[4] El-Damrawi, G., Hassan, A., Doweidar, H. and Shaboub, A. (2017) Structural Studies on $\mathrm{Ag}_{2} \mathrm{O}-\mathrm{P}_{2} \mathrm{O}_{5}$ Glasses. New Journal of Glass and Ceramics, 7, 77. https://doi.org/10.4236/njgc.2017.73007

[5] Sidhu, S.K. and Nicholson, J.W. (2016) A Review of Glass-Ionomer Cements for Clinical Dentistry. Journal of Functional Biomaterials, 7, 16. https://doi.org/10.3390/jfb7030016

[6] Mount, G.J. (2002) Color Atlas of Glass Ionomer Cement. 2nd Edition, Martin Dunitz Limited, London.

[7] Shahid, S., Hassan, U., Billington, R.W., Hill, R.G. and Anderson, P. (2014) Glass Ionomer Cements: Effect of Strontium Substitution on Esthetics, Radiopacity and Fluoride Release. Dental Materials, 30, 308-313. https://doi.org/10.1016/j.dental.2013.12.003

[8] Hill, R.G., Stamboulis, A. and Law, R.V. (2006) Characterisation of Fluorine Containing Glasses by ${ }^{19} \mathrm{~F}, 27 \mathrm{Al},{ }^{29} \mathrm{Si}$ and ${ }^{31} \mathrm{P}$ MAS-NMR Spectroscopy. Journal of Dentistry, 34, 525-532. https://doi.org/10.1016/j.jdent.2005.08.005

[9] El Damrawi, G., Hassan Akabdelghany, M. and Baghdady, H. (2017) Chromium Fluoride Containing Bioactive Glasses. Journal of Advances in Physics, 14, 9.

[10] Nicholson, J.W., Czarnecka, B. and Limanowska-Shaw, H. (1999) The Long-Term Interaction of Dental Cements with Lactic Acid Solutions. Journal of Materials Science: Materials in Medicine, 10, 449-452. https://doi.org/10.1023/A:1008991422909

[11] El-Damrawi, G., Doweidar, H., Kamal, H. and Hassan, A. (2017) Characterization of New Categories of Bioactive Based Tellurite and Silicate Glasses. Silicon, 9, 503-509.

[12] Wilson, A.D. (1974) Alumino-Silicate Polyacrylic Acid Cement. British Polymer Journal, 6, 165-179. https://doi.org/10.1002/pi.4980060303 
[13] Song, J.-L. and Wang, X.-J. (2016) Crystal Structure of Mixed-Metal Phosphite, $\mathrm{Pb}_{2} \mathrm{Ga}\left(\mathrm{HPIIIO}_{3}\right)_{3}\left(\mathrm{PVO}_{3}\right)$. Structural Chemistry and Crystallography Communication, 2.

[14] Wu, D.-S., Cheng, W.-D., Li, X.-D., Lan, Y.-Z., Chen, D.-G., Zhang, Y., Zhang, H. and Gong, Y.-J. (2004) Syntheses, Crystal and Electronic Structures, and Linear Optics of LiMBO3 $(\mathrm{M}=\mathrm{Sr}, \mathrm{Ba})$ Orthoboratese. The Journal of Physical Chemistry A, 108, 1837-1843.

[15] Armand, P., Lignie, A., Beaurain, M. and Papet, P. (2014) Flux-Grown Piezoelectric Materials: Application to $\alpha$-Quartz Analogues. Crystals, 4, 168-189. https://doi.org/10.3390/cryst4020168

[16] Sidhu, S.K. (2010) Clinical Evaluations of Resin-Modified Glass-Ionomer Restorations. Dental Materials, 26, 7-12. https://doi.org/10.1016/j.dental.2009.08.015

[17] Engqvist, H., Schultz-Walz, J.E., et al. (2004) Calcium-Aluminate as Biomaterial Synthesis, Design and Evaluation. Biomaterials, 25, 2781-2787.

[18] Llusar, M., Escuder, B., de Dios López-Castro., J., Trasobares, S. and Monrós, G. (2017) Gels as Templates for Transcription. Gels, 3, 23.

[19] Bu, W., Chen, H., Hua, Z., Liu, Z., Huang, W., Zhang, L. and Shi, J. (2004) Surfactant-Assisted Synthesis of Tb(III)-Doped Cerium Phosphate Single-Crystalline Nanorods with Enhanced Green Emission. Applied Physics Letters, 85, 4307-4309. https://doi.org/10.1063/1.1818346

[20] Young, A.M., Herpa, A., Searson, G.P., Chottlander, B.S. and Waters, D.N. (2000) Hydrothermal Synthesis and Luminescent Properties of Ordered Sphere $\mathrm{CePO}_{4}$. Biomaterials, 21, 1971-1979.

[21] Yang, M., You, H., Zheng, Y., Liu, K., Jia, G., Song, Y., Huang, Y., Zhang, L. and Zhang, H. (2009) Hydrothermal Synthesis and Luminescent Properties of Novel Ordered Sphere $\mathrm{CePO}_{4}$ Hierarchical Architectures. Inorganic Chemistry, 48, 11559-11565. https://doi.org/10.1021/ic901829v

[22] Fujihara, S., Takano, Y. and Kitsuda, M. (2015) Microstructural Aspects of the Ce$\mathrm{PO}_{4}: \mathrm{Tb}^{3+}$ Phosphor for Luminescence Sensing. International Journal of Applied Ceramic Technology, 12, 411-417. https://doi.org/10.1111/ijac.12173

[23] Pusztai, P., Tóth-Szeles, E., Horváth, D., Tóth, Á., Kukovecz, Á. and Kónya, Z. (2015) A Simple Method to Control the Formation of Cerium Phosphate Architectures. CrystEngComm, 17, 8477-8485. https://doi.org/10.1039/C5CE01404B

[24] Hartgerink, J.D., Beniash, E. and Stupp, S.I. (2001) Self-Assembly and Mineralization of Peptide-Amphiphile Nanofibers. Science, 294, 1684-1688. https://doi.org/10.1126/science.1063187

[25] Aoki, K., Nagano, K. and Iitaka, Y. (1971) The Crystal Structure of L-Arginine Phosphate Monohydrate. Acta Crystallographica Section B, B27, 11-23. https://doi.org/10.1107/S056774087100164X

[26] Heinemann, S., Heinemann, C., Jäger, M., Neunzehn, J., Wiesmann, H.P. and Hanke, T. (2011) Effect of Silica and Hydroxyapatite Mineralization on the Mechanical Properties and the Biocompatibility of Nanocomposite Collagen Scaffolds. Applied Materials \& Interfaces, 3, 4323-4331. https://doi.org/10.1021/am200993q

[27] Miravet, J.F. and Escuder, B. (2005) Reactive Organogels: Self-Assembled Support for Functional Materials. Organic Letters, 7, 4791-4794.

https://doi.org/10.1021/ol0514045

[28] Roy, G., Miravet, J.F., Escuder, B., Sanchez, C. and Llusar, M. (2006) Morphology Templating of Nanofibrous Silicathrough pH-Sensitive Gels: "In Situ" and 
"Post-Diffusion" Strategies. Journal of Materials Chemistry, 16, 1817-1824. https://doi.org/10.1039/B601561A

[29] Suzuki, M., Nakajima, Y., Sato, T., Shirai, H. and Hanabusa, K. (2006) Fabrication of $\mathrm{TiO}_{2}$ Using L-Lysine-Based or Ganogelators as Organic Templates: Control of the Nanostructures. Chemical Communications, No. 4, 377-379.

https://doi.org/10.1039/B510302A

[30] Delbecq, F. (2014) Supramolecular Gels from Lipopeptide Gelators: Template Improvement and Strategies for the In-Situ Preparation of Inorganic Nanomaterials and for the Dispersion of Carbon Nanomaterials. Advances in Colloid and Interface Science, 209, 96-108. https://doi.org/10.1016/j.cis.2014.02.018 